\title{
MUSINGS
}

\section{Musings on genome medicine: Hepatitis C}

\author{
David G Nathan and Stuart H Orkin
}

\begin{abstract}
Hepatitis $C$ is a viral disease transmitted principally by blood, which affects millions of people worldwide. A significant proportion of those affected develop severe liver disease as a result. Only a fraction of patients are responsive to interferon treatment, highlighting the need for further research into genetic factors involved in response to therapy in order to optimize treatment. The only current approach for end-stage disease is liver transplant, which ironically does not cure the condition, and thus poses a clinical dilemma in the face of liver-donor shortage.
\end{abstract}

One hundred and fifty million people are infected by hepatitis $\mathrm{C}$ virus $(\mathrm{HCV})$ worldwide, and chronic hepatitis $\mathrm{C}$ is now the leading indication for liver transplantation in the US [1]. Transmitted principally by blood, HCV is passed by transfusion of inadequately screened blood and blood products, and by intravenous drug use; sexual and vertical transmission also occur, but at substantially lower rates than in other blood-borne viral infections. Unsterile dental equipment, accidental needle punctures in medical facilities, and tattooing are also linked to transmission. Following acquisition of infection, 70 to $85 \%$ of patients will develop persistent viremia, usually for the duration of their lives. Not all of these will develop liver failure, however - infection is often indolent for long periods. Nonetheless, two decades after infection about $20 \%$ of HCV-infected subjects will have developed endstage liver disease [2].

Hepatitis $C$ is now a more common cause of cirrhosis than alcoholism. Though chronic hepatitis is the major result of $\mathrm{HCV}$ infection, there are other manifestations of the disease that stem from chronic inflammation and associated immune cell stimulation with cytokine release. These include arthritis, antibody-mediated thrombocytopenia, itching, porphyria cutanea tarda, dermatitis, glomerulonephritis and cryoglobulinemia.

*Correspondence: david_nathan@dfci.harvard.edu

Dana-Farber Cancer Institute, 44 Binney Street, Boston, MA 02115, USA
$\mathrm{HCV}$ is a small $(50 \mathrm{~nm})$ single-stranded RNA member of the flaviviridae family. The RNA has one open reading frame, preceded by a ribosome-binding site within a UTR (untranslated region). The open reading frame encodes a 3,011 amino acid protein that is cleaved into several different proteins by proteases of viral and cellular origins. The amino acid sequences include nucleocapsid, envelope, protease, helicase, transmembrane, and RNA polymerase proteins. The $\mathrm{HCV}$ RNA polymerase is highly error prone, and the sequences of HCV genomes display enormous amounts of variation. Six different genotypes of HCV have been characterized. They differ from one another at nearly one-third of their nucleotide positions, but in practice are defined by mutations in the 5'UTR. These six genotypes are stable, heritable variants that differ in their geographic distribution. Superimposed on this already substantial variation is the fact that large numbers of mutations occur in any given individual's $\mathrm{HCV}$ isolate over time - that is, as in HIV, each new infection gives rise to a cloud of sequence variants descended from the original infection; this cloud is sometimes referred to as a 'quasispecies'. This extraordinary sequence diversity renders the virus very resistant to standard immune responses and inhibits the production of a useful preventive vaccine. Thus the virus is very difficult to clear when infection occurs.

The two coat proteins of the virus are heavily glycosylated and recognize receptors on the hepatocyte. Though not entirely proven, these receptors are thought to be CD81, claudin-1 and occludin [3-5]. Virions replicate at an enormous rate in hepatocytes, from which they are released into the blood (they may invade monocytes and B cells as well, but this is uncertain). The titer of virus in the blood may therefore provide a fairly accurate index of the hepatic load of virus. Recently a relatively wellconserved sequence of the non-coding region has been identified, permitting the development of an inexpensive and highly accurate diagnostic polymerase chain reaction (PCR)-based blood test for the virus and its titer [6].

Treatment of hepatitis $C$ was unsuccessful until interferon alfa was introduced in the 1980s. This protein activates the janus kinase/signal transducers and activators of transcription (JAK/STAT) signaling pathway to induce the transcription of interleukins and caspases that kill viral loaded cells [7], but the toxicity of the 
thrice-weekly treatment was considerable and the original remission rate was only 10 to $15 \%$. Particularly poor results were seen in those infected with viral genotype 1 , which accounts for $65 \%$ of US cases of hepatitis C including the bulk of Caucasian and the vast majority of American Black patients [8]. The addition of ribavirin brought the remission rate up to 20 to $25 \%$, and a change to weekly pegylated interferon alfa further increased the response rate [9]. But the treatment remains difficult, with side-effects that resemble the cytokine-releasing consequences of cancer chemotherapy, and the hemolytic anemia induced by ribavirin weakens patients still further. American patients with genotype 1 continue to respond less well than those with genotypes 2 and 3, but nonetheless a significant subset of genotype 1 carriers do benefit from treatment. Given the toxicities of interferon/ ribavirin, it would be very useful to be able to predict which patients might fall into the responder subclass.

Connected to this, a startling advance has recently been made by Ge, Thomas and their co-workers $[10,11]$, who have shown that a polymorphism in close proximity to the $I L 28 B$ gene that encodes interferon lambda 3 predicts both spontaneous clearance of $\mathrm{HCV}$ and response to interferon and ribavirin treatment in genotype 1 hepatitis $\mathrm{C}$ infection. Clearance and response to therapy are not affected by the polymorphism in those with genotype 2 and 3 infections. The reasons for these disparities are not at all evident, since the genotypes are not associated with any known protein differences.

Finally, the treatment of hepatitis C-induced chronic liver failure with liver transplantation illustrates the dilemma posed by the growth of technology in medical care. The procedure is not curative. Indeed, all such liver transplants become re-infected by persistent virus, and in some patients the march to secondary cirrhosis is accelerated, necessitating a second transplant. Ironically, alcoholic cirrhotics are routinely denied transplants in the current donor-liver shortage because it is thought that their bibulous habits cannot be broken. Yet patients with hepatitis $C$ receive transplants routinely, even though their livers are doomed to be re-infected and cirrhosis induced at a far faster rate than that caused by alcohol. Since the natural progression of the disease takes two or more decades, and since most patients come to transplant in their $50 \mathrm{~s}$ or $60 \mathrm{~s}$, most do not require a second transplant but the costs of these decisions are massive.

\section{Abbreviations}

HCV, hepatitis C virus; JAK, janus kinase; PCR, polymerase chain reaction; STAT, signal transducers and activators of transcription; UTR, untranslated region.

\section{Acknowledgements}

The authors are grateful to Maureen Jonas MD and Chinwe Ukomadu MD for their valuable help in the preparation of this discussion, and particularly express their appreciation to Don Ganem MD for his careful review of the manuscript and his important suggestions.

Published: 27 January 2010

\section{References}

1. Muir AJ, Bornstein JD, Killenberg PG, Atlantic coast hepatitis treatment group: Peginterferon alfa- $2 \mathrm{~b}$ and ribavirin for the treatment of chronic hepatitis $\mathrm{C}$ in blacks and non-Hispanic whites. N Engl J Med 2004, 350:2265-2271.

2. NIH Consensus Statement on Management of Hepatitis C: 2002. NIH Consens State Sci Statements 2002, 19:1-46.

3. Perrault M, Pecheur El: The hepatitis $C$ virus and its hepatic environment: a toxic but finely tuned partnership. Biochem J 2009, 423:303-314.

4. Cukierman $L$, Meertens $L$, Bertaux C, Kajumo F, Dragic T: Residues in a highly conserved claudin-1 motif are required for hepatitis $C$ virus entry and mediate the formation of cell-cell contacts. J Virol 2009, 83:5477-5484.

5. Cheng JC, Yeh YJ, Pai LM, Chang ML, Yeh CT: 293 cells over-expressing human ADI1 and CD81 are permissive for serum-derived hepatitis $C$ virus infection. J Med Virol 2009, 81:1560-1568.

6. Lindenbach $B D$, Rice $C M$ : Unravelling hepatitis $C$ virus replication from genome to function. Nature 2005, 436:933-938.

7. Johansson N, Westermarck J, Leppä S, Häkkinen L, Koivisto L, López-Otín C, Peltonen J, Heino J, Kähäri VM: Collagenase 3 (matrix metalloproteinase 13) gene expression by $\mathrm{HaCaT}$ keratinocytes is enhanced by tumor necrosis factor alpha and transforming growth factor beta. Cell Growth Differ 1997, 8:243-250

8. Jeffers $L$, Cassidy W, Howell CD, Hu S, Reddy KR: Peginterferon alfa-2a (40 kd) and ribavirin for black American patients with chronic HCV genotype 1. Hepatology 2004, 39:1702-1708.

9. Vogel W: Peginterferon-alpha $2 \mathrm{a}(40 \mathrm{kDa}) /$ ribavirin combination for the treatment of chronic hepatitis $C$ infection. Expert Rev Anti Infect Ther 2003, 1:423-431.

10. Ge D, Fellay J, Thompson AJ, Simon JS, Shianna KV, Urban TJ, Heinzen EL, Qiu P, Bertelsen AH, Muir AJ, Sulkowski M, McHutchison JG, Goldstein DB: Genetic variation in IL28B predicts hepatitis $C$ treatment-induced viral clearance. Nature 2009, 461:399-401.

11. Thomas DL, Thio CL, Martin MP, Qi Y, Ge D, O'Huigin C, Kidd J, Kidd K, Khakoo SI, Alexander G, Goedert JJ, Kirk GD, Donfield SM, Rosen HR, Tobler LH, Busch MP, McHutchison JG, Goldstein DB, Carrington M: Genetic variation in IL28B and spontaneous clearance of hepatitis C virus. Nature 2009, 461:798-801.

doi:10.1186/gm125

Cite this article as: Nathan DG, Orkin SH: Musings on genome medicine:

Hepatitis C. Genome Medicine 2010, 2:4. 